\title{
Evaluation of attenuated Salmonella choleraesuis- mediated inhibin recombinant DNA vaccine in rats
}

\author{
F.M. Hui ${ }^{1}$, C.L. Meng ${ }^{1}$, N.N. Guo ${ }^{1}$, L.G. Yang ${ }^{2}$, F.X. Shi ${ }^{1}$ and D.G. Mao ${ }^{1}$ \\ ${ }^{1}$ College of Animal Science and Technology, Nanjing Agricultural University, \\ Nanjing, China \\ ${ }^{2}$ College of Animal Science and Technology, Huazhong Agricultural University, \\ Wuhan, China \\ Corresponding author: D.G. Mao \\ E-mail: maodagan@njau.edu.cn
}

Genet. Mol. Res. 13 (3): 6113-6125 (2014)

Received July 30, 2013

Accepted November 27, 2013

Published August 7, 2014

DOI http://dx.doi.org/10.4238/2014.August.7.27

\begin{abstract}
DNA vaccination has been studied intensively as a potential vaccine technology. We evaluated the effect of an attenuated Salmonella choleraesuis-mediated inhibin DNA vaccine in rats. First, 15 rats were treated with different doses of an inhibin vaccine to evaluate vaccine safety. Next, 30 rats were divided into 3 groups and injected intramuscularly with the inhibin vaccine two (T1) or three times (T2) or with control bacteria (Con) at 4-week intervals. The inhibin antibody levels increased [positive/negative well $(\mathrm{P} / \mathrm{N})$ value: $\mathrm{T} 1$ vs $\mathrm{Con}=2.39$ \pm 0.01 vs $1.08 \pm 0.1$; T2 vs $\mathrm{Con}=2.36 \pm 0.1$ vs $1.08 \pm 0.1, \mathrm{P}<0.05]$ at week 2 and were maintained at a high level in T1 and T2 until week 8, although a small decrease in T2 was observed at week 10. Rats in the T1 group showed more corpora lutea compared with the Con group $(10.50 \pm 0.87$ vs $7.4 \pm 0.51, \mathrm{P}<0.05)$. Estradiol $(0.439 \pm 0.052$ vs 0.719 $\pm 0.063 \mathrm{ng} / \mathrm{mL}, \mathrm{P}<0.05)$ and progesterone $(1.315 \pm 0.2$ vs $0.737 \pm 0.11$ $\mathrm{ng} / \mathrm{mL}, \mathrm{P}<0.05$ ) levels differed significantly at metestrus after week 10 between rats in the $\mathrm{T} 1$ and Con groups. However, there were no
\end{abstract}


significant differences in body, ovary, uterus weights, or pathological signs in the ovaries after immunization, indicating that this vaccine is safe. In conclusion, the attenuated S. choleraesuis-mediated inhibin vaccine may be an alternative to naked inhibin plasmids for stimulating ovarian follicular development to increase the ovulation rate in rats.

Key words: Inhibin; DNA vaccine; Ovary; Salmonella choleraesuis; Rat

\section{INTRODUCTION}

Inhibin, a hetero-dimeric glycoprotein comprised of two subunits in the form of inhibin $A\left(\alpha \beta_{A}\right)$ and inhibin $B\left(\alpha \beta_{B}\right)$ (de Kretser et al., 2000), plays an essential role in regulating pituitary follicle-stimulating hormone (FSH) synthesis and secretion. Immunization against inhibin has been used to increase animal reproduction and fertility. The development of an inhibin immunogen has involved conventional protein and novel DNA phases. Many studies have demonstrated that immunization against native inhibin preparations purified from follicular fluid (Morris et al., 1991; Sewani-Rusike and Dakwa, 2000), those that are chemically synthesized (Tannetta et al., 1998), or genetic fragments of the inhibin $\alpha$-subunit (O'Shea et al., 1993; Li et al., 2009, 2011; Wang et al., 2009) stimulated follicular development and enhanced oocyte quality, maturation competence (Li et al., 2009), and sperm quality (Avital-Cohen et al., 2012). The preparation and purification of a conventional vaccine is timeconsuming and labor-intensive. Because of their convenience, stability, and cost, a variety of DNA vaccines encoding the inhibin $\alpha(1-32)$ gene or a fusion with the $\mathrm{S}$ gene of the hepatitis B surface antigen have been developed (Han et al., 2008; Wang et al., 2012), and the results showed that an inhibin DNA vaccine was a promising tool for improving animal fertility. However, DNA vaccines face several problems such as low-uptake efficiency (Greenland et al., 2007), dose-dependence (Huang et al., 2008), low immunogenicity in humans and large animals (Melkebeek et al., 2007), and, particularly, antibiotic-resistance-based plasmid selection systems (Galen et al., 2010), making it important to develop an alternative approach for inhibin DNA vaccination.

Attenuated Salmonella choleraesuis can transfer plasmids encoding foreign antigens under the control of a eukaryotic promoter to host cells, protecting against the bacteria itself, allowing simultaneous immune responses specific to the heterologous antigen(s) (Kwon et al., 2007), and strong humoral and cellular responses (Yang et al., 2010). Therefore, this system is considered to be an ideal candidate for the delivery of DNA vaccines. In addition, incorporation of a balanced lethal vector system can minimize the risks of antibiotic use (TorresEscobar et al., 2010).

In our present study, we applied a balanced lethal bacteria vector system for the inhibin vaccine. This system involved the use of an artificial mutant of an S. choleraesuis C500 strain capable of double deletion of the cyclic AMP receptor protein (crp) and $\beta$-aspartic semialdehyde dehydrogenase (asd) genes, and an inhibin recombinant plasmid, pVAX-IS-asd (pXAIS), without antibiotic resistance based on a previous study (Han et al., 2008; Zhen et al., 2009). The objectives of this study were to determine the safe dosage of the S. choleraesuismediated vaccine and to assess the effect of this vaccine on the serum antibody titer against inhibin and follicular development in rats. 


\section{MATERIAL AND METHODS}

\section{Animals and vaccines}

Adult female Sprague-Dawley rats with an initial weight of 200-250 g were purchased from the Experiment Animal Center of Nanjing Medical University, China, and were housed with five animals per cage under a controlled temperature of $23^{\circ} \pm 2^{\circ} \mathrm{C}$, and fed commercial food and tap water ad libitum. All animals were treated according to the Institutes of Health Guides for the Care and Use of Laboratory Animals, Nanjing Agricultural University.

The vaccine was supplied by Dr. LG Yang (Huazhong Agricultural University) (Zhen et al., 2009). The inoculation vaccine was prepared from cultures of recombinant $S$. choleraesuis C500 containing pXAIS (inhibin plasmid) or pVAX-asd (control plasmid). Recombinant $S$. choleraesuis C500 were incubated at $37^{\circ} \mathrm{C}$ with shaking at $200 \mathrm{rpm}$ in LuriaBertani broth to $\mathrm{A}_{600}=0.7-0.8$. The culture medium was pelleted at $2000 \mathrm{~g}$ for $10 \mathrm{~min}$ at $4{ }^{\circ} \mathrm{C}$ and then resuspended in $10 \mathrm{~mL} 0.85 \% \mathrm{NaCl}$ followed by centrifugation and resuspension. Doses of bacteria in suspension were calculated according to the formula: $\mathrm{A}_{600} \times 8 \times 10^{10}$ colony-forming units $(\mathrm{CFU}) / \mathrm{mL}$ x suspension volume $(\mathrm{mL})$. The inoculated volume was 160 $\mu \mathrm{L}$ bacteria and $40 \mu \mathrm{L}$ alhydrogel aluminum hydroxide as an adjuvant.

\section{Experimental design}

Two trials were conducted. The first was designed to explore the safe dosage of the vaccine. Fifteen rats were randomly divided into 3 groups $(\mathrm{N}=5)$ and were immunized intramuscularly (im) with $200 \mu \mathrm{L} 10^{8}, 10^{9}$, and $10^{10} \mathrm{CFU}$ attenuated $S$. choleraesuis-mediated pXAIS to determine a safe dosage for the rats. The rats were observed for 14 days for any adverse reaction. On day 15 , rats were sacrificed under anesthesia with ether. The uteri, lungs, spleens, kidneys, and jejuna were collected for histological analysis by hematoxylin and eosin staining.

A second trial was designed to evaluate the effect of the vaccine on follicular development in rats. Thirty rats were randomly divided into 3 groups $(\mathrm{N}=10)$ and given primary and booster immunizations with pXAIS (T1, T2) and pVAX-asd (Con) at a dosage of $10^{10} \mathrm{CFU}$ bacteria based on previous results. Rats in the T2 and Con groups were given an additional booster immunization. All booster immunizations were given at intervals of 4 weeks. Serum was harvested to evaluate the level of antibodies against inhibin. The whole body, ovaries, and uteri were weighed, and the ovaries were collected to evaluate follicular development.

\section{Hematoxylin and eosin staining}

Tissues were fixed in 4\% paraformaldehyde at room temperature for $24 \mathrm{~h}$, embedded in paraffin, sectioned serially at $10 \mu \mathrm{m}$, and stained with hematoxylin and eosin. These sections were analyzed for morphological changes indicative of pathological signs, except for the ovaries, which were analyzed for ovulation number.

\section{Serum inhibin antibody enzyme-linked immunosorbent assay (ELISA)}

Serum samples were collected from the tail vein at weeks $0,2,4,6,8$, and 10 under 
anesthesia with ether. Inhibin antibody levels (diluted at 1:100) were determined using an ELISA as detailed below.

A 96-well immunoplate (Greiner Bio-One; Frickenhausen, Germany) was coated with inhibin $\alpha$ (1-32) (I8641; Sigma, St. Louis, MO, USA) in fresh buffer (0.015 $\mathrm{M} \mathrm{Na}_{2} \mathrm{CO}_{3}, 0.035$ $\mathrm{M} \mathrm{NaHCO}_{3}, \mathrm{pH} 9.6$ ) at $100 \mathrm{ng} / 100 \mu \mathrm{L}$ per well at $4^{\circ} \mathrm{C}$ overnight. The next morning, the plate was washed three times with phosphate-buffered saline (PBS) containing $0.05 \%$ Tween 20. Next, wells were blocked with $2 \%$ glutin-PBS for $2 \mathrm{~h}$ at $37^{\circ} \mathrm{C}$ before being incubated with serum samples diluted with $0.1 \%$ bovine serum albumin-PBS for $1 \mathrm{~h}$ at $37^{\circ} \mathrm{C}$. After three washes, the plate was incubated for another $40 \mathrm{~min}$ at $37^{\circ} \mathrm{C}$ with horseradish peroxidase-labeled goat anti-rat IgG antibodies (1:2000; Sigma). Next, $150 \mu \mathrm{L}$ tetramethylbenzidine-peroxidase substrate was added to each well and the plate was incubated for $20 \mathrm{~min}$. The reaction was stopped by addition of $2 \mathrm{M} \mathrm{H}_{2} \mathrm{SO}_{4}$. The optical density (OD) at $450 \mathrm{~nm}$ was recorded using a plate reader (Bio-Rad; Hercules, CA, USA).

Results are reported as OD ratios of positive/negative well $(\mathrm{P} / \mathrm{N})$, where $\mathrm{P}$ and $\mathrm{N}$ represent the OD values of the tested samples and negative control samples, respectively (Ebel et al., 2002). A P/N value $>2.0$ and an OD value $>0.2$ was considered to be positive, and partial samples were tested further using a titration method to determine the antibody titer.

\section{Ovary examination}

After the second booster immunization, the estrous cycle was determined by vaginal smearing twice each day. Two weeks later, rats at the metestrus stage were sacrificed. The whole bodies, ovaries, and uteri were weighed and hematoxylin and eosin staining was applied to observe the ovarian histology. The corpora lutea were also counted.

\section{Radioimmunoassay (RIA) for serum estradiol and progesterone}

Sera were collected by heart puncture when rats were sacrificed at the metestrus stage to detect estradiol and progesterone with RIA kits (Beijing North Bio-Engineering Institution, Beijing, China) following the manufacturer protocol. The assay sensitivity was $2 \mathrm{pg} / \mathrm{mL}$ for estradiol and $0.02 \mathrm{ng} / \mathrm{mL}$ for progesterone. The inter- and intra-assay coefficients of variation were 10 and $<15 \%$, respectively, for both estradiol and progesterone.

\section{Statistical analysis}

Data are reported as means \pm SE. Statistical analyses were performed using SPSS 17.0 (SPSS, Inc., Chicago, IL, USA). Data were analyzed by one-way analysis of variance (ANOVA) followed by Fisher protected least significant difference (LSD) tests. $\mathrm{P}<0.05$ was considered to be statistically significant.

\section{RESULTS}

\section{Optimization of safe vaccine dosage}

To investigate the optimal vaccine dose, rats were injected with serial doses of pXAIS 
mediated by attenuated $S$. choleraesuis. During the 14-day period of immunization, all rats survived. Body weight gains increased without significant differences among groups (data not shown). Following sacrifice, spleens, lungs, jejuna, kidneys, and uteri were collected for histopathology examination, and these tissues appeared to be normal, as shown in Figure 1. The vaccine appeared to be safe up to a dose of $10^{10} \mathrm{CFU}$. These results suggest that the inhibin vaccine is biologically safe and that $10^{10} \mathrm{CFU}$ can be used in subsequent studies.

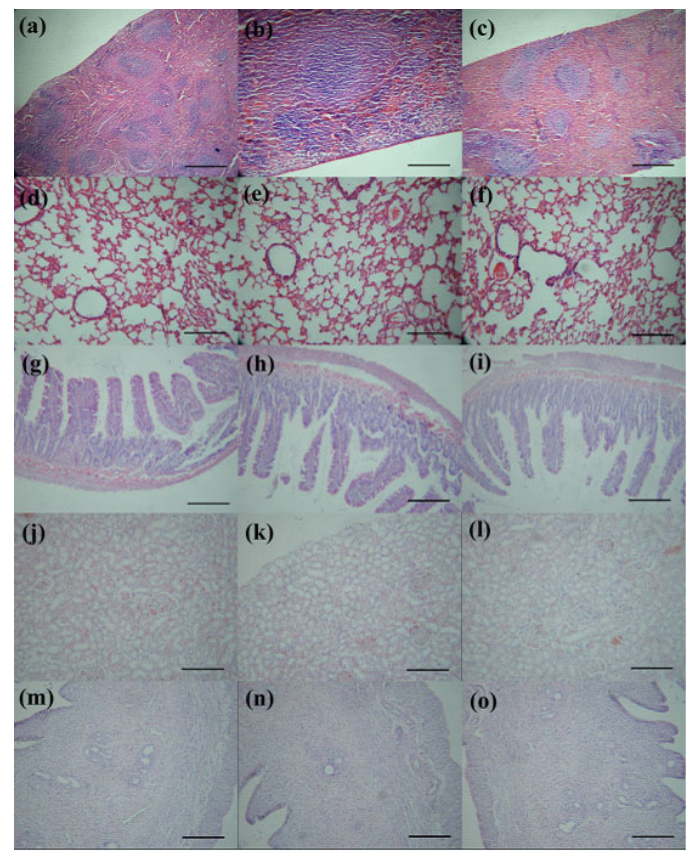

Figure 1. Salmonella choleraesuis-mediated inhibin DNA immunization does not show distinct pathological signs. SD rats were immunized $i m$ with $10^{8}$ (left line), $10^{9}$ (middle line) or $10^{10} \mathrm{CFU}$ (right line) attenuated S. choleraesuismediated inhibin vaccine for 14 days. Tissues (from top to bottom line: a.-c. spleen; d.-f. lung; g.-i. jejunum; j.-l. kidney; m.-o. uterus) were collected and detected by hematoxylin and eosin staining. Scale bars $=20 \mu \mathrm{m}$.

\section{Serum inhibin antibody titers after immunization with the vaccine}

To evaluate the attenuated S. choleraesuis-mediated inhibin DNA vaccine on inhibin antibodies, ELISA was used to detect antibody levels against inhibin. $\mathrm{P} / \mathrm{N}$ values in groups $\mathrm{T} 1$ and T2 at week 2 were greater than those at week $0(\mathrm{P}<0.01)$, and remained nearly unchanged until week 8, although a booster was given at week 4 . At week $8, \mathrm{~T} 2$, but not T1, rats were given another booster. Interestingly, the inhibin antibody level in T2 rats declined significantly $(\mathrm{P}<0.05)$, while it did not change in T1 rats (Figure 2). Recombinant S. choleraesuis C500 containing the pXAIS injection produced positive individuals with inhibin antibody $(\mathrm{P} / \mathrm{N}>2)$. Two weeks after primary immunization, the ratio of positive rats reached $60 \%(6 / 10)$ in both $\mathrm{T} 1$ and T2, whereas positivity decreased to 40\% (4/10) and 20\% (2/10), respectively, at week 10 .

Titers of the inhibin antibody after immunization in positive rats were detected using a titration method. Results showed that one rat in the $\mathrm{T} 2$ group showed a titer inhibin antibody of 1:6400 after primary and booster immunization (Table 1). 


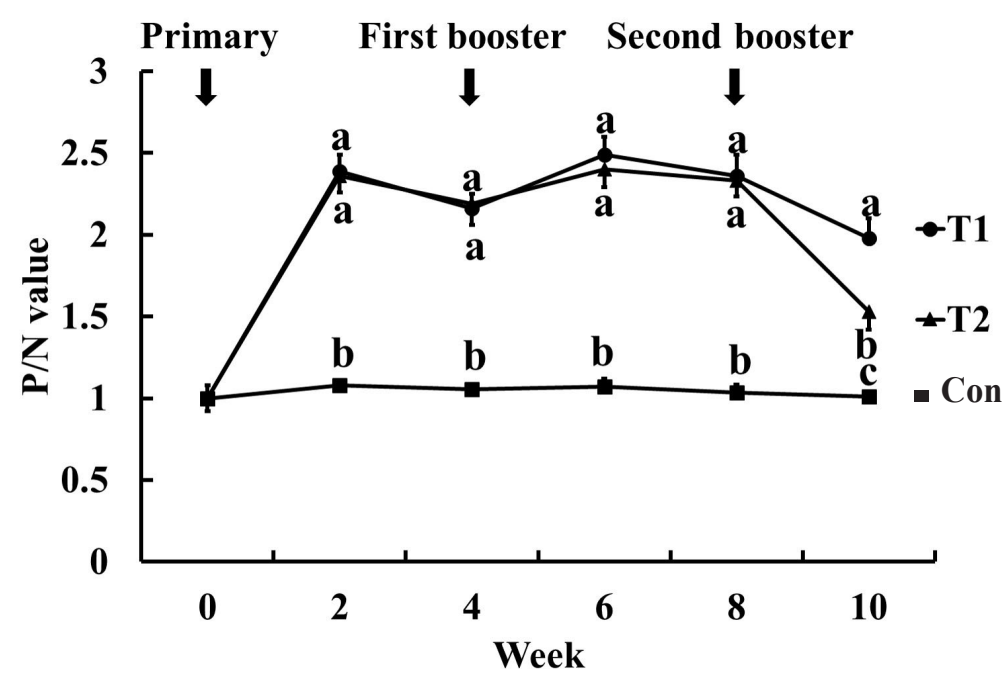

Figure 2. Salmonella choleraesuis-mediated inhibin DNA vaccine stimulates the production of inhibin antibody. Rats were immunized with $10^{10} \mathrm{CFU}$ S. choleraesuis-mediated inhibin vaccine for 2 times (T1), 3 times (T2) or with control bacteria for 3 times (Con). Inhibin antibody was detected by ELISA. Data are reported as means $\pm \mathrm{SE}$. Statistical difference was determined by one-way ANOVA followed by Fisher protected least significant difference (LSD) tests. The $\mathrm{P} / \mathrm{N}$ value increased significantly after the primary immunization of inhibin vaccine $(\mathrm{P}<0.01)$ and kept at high level throughout the experiment. Different letters denote significant differences $(\mathrm{P}<0.05)$ among groups.

\begin{tabular}{|c|c|c|c|c|c|c|c|c|}
\hline \multirow[t]{2}{*}{ Time } & \multicolumn{7}{|c|}{ OD value of each dilution } & \multirow[t]{2}{*}{ Control } \\
\hline & $1: 100$ & $1: 200$ & $1: 400$ & $1: 800$ & $1: 1600$ & $1: 3200$ & $1: 6400$ & \\
\hline Week 2 & 0.526 & 0.390 & 0.332 & 0.281 & 0.236 & 0.124 & 0.028 & 0 \\
\hline Week 6 & 0.550 & 0.234 & 0.130 & 0.096 & 0.044 & 0.014 & 0.006 & 0 \\
\hline
\end{tabular}

Sera detected from a positive rat immunized with $10^{10} \mathrm{CFU}$ Salmonella choleraesuis-mediated inhibin vaccine for 3 times (T2 group). Control $=$ serum sample from the same rat at week 0 . The titer of inhibin antibody 2 weeks after primary (week 2) and booster immunization (week 6) approached to 1:6400.

\section{Ovulation examination}

To assess the effect of the inhibin vaccine on the ovary index, rats were sacrificed at the metestrus stage after week 10. Representative ovarian sections stained with hematoxylin and eosin are shown in Figure 3. The amounts of fresh corpora lutea counted from ovarian sections were $10.50 \pm 0.87$ for rats with a single booster immunization (T1) and $7.33 \pm 0.88$ and $7.4 \pm 0.51$ in rats with two booster immunizations (T2) and control rats (Con), respectively. T1 rats showed significantly more corpora lutea than the other two groups $(\mathrm{P}<0.05$; Figure 4$)$. Body weight gains throughout the experiment increased with time and showed no significant differences among groups $(\mathrm{P}>0.05$; Figure $5 \mathrm{~A})$. The ovary and uterus weights showed no differences among groups $(\mathrm{P}>0.05$; Figure $5 \mathrm{~B}$ and $\mathrm{C})$. 


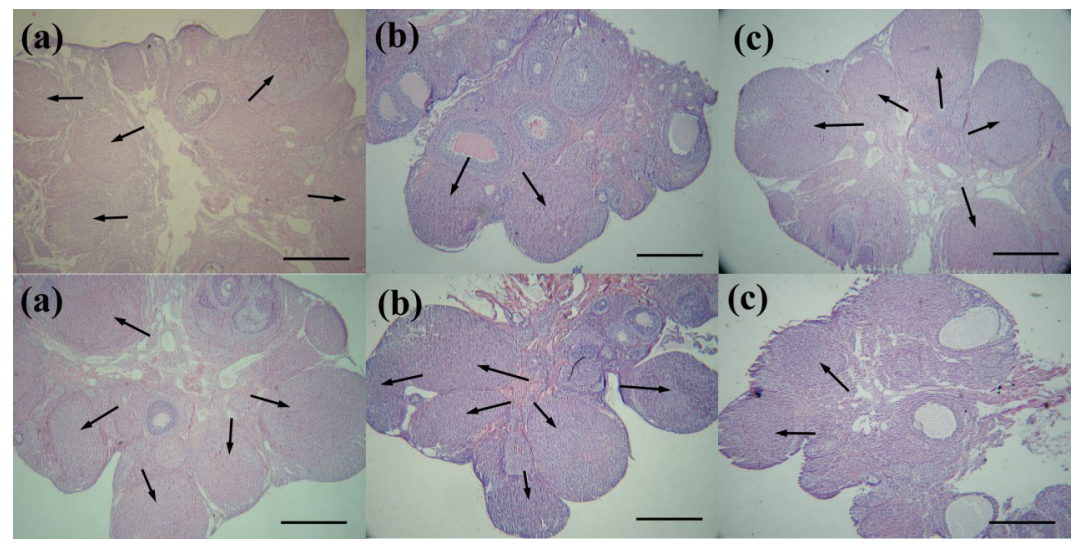

Figure 3. Representative ovarian sections from rats at metestrus stage. Rats were immunized as in Figure 2, and then were sacrificed at metestrus stage after week 10. Ovaries were collected and detected by hematoxylin and eosin staining. The figures only show parts of the ovaries of different individuals from T1 (a), T2 (b) and Con (c). Arrows represent corpus luteum. Scale bars $=50 \mu \mathrm{m}$.

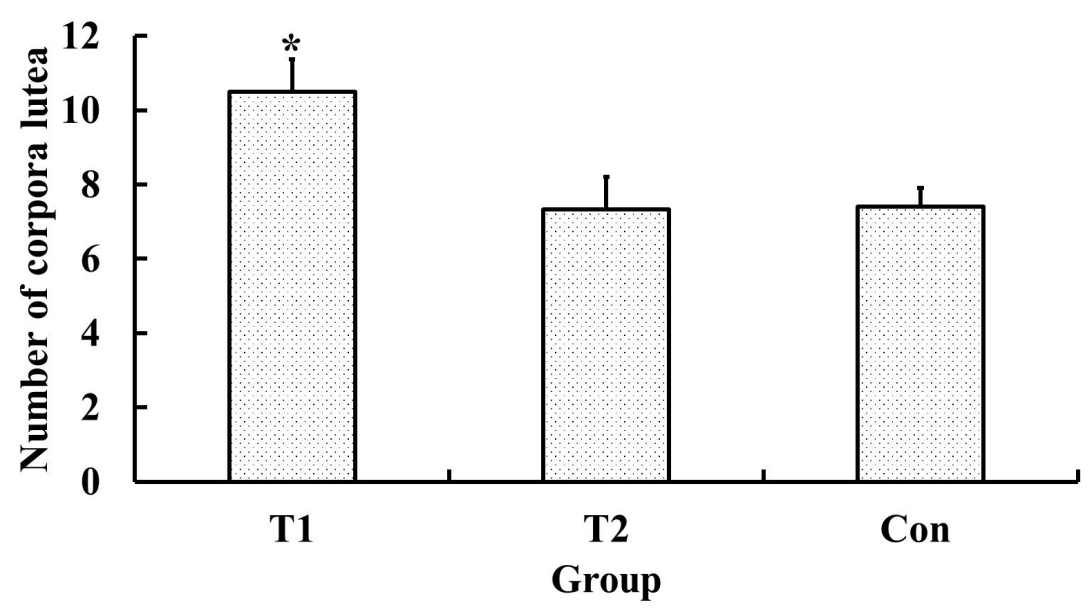

Figure 4. Number of corpora lutea after inhibin DNA immunization. Rats were processed as in Figure 3 and corpora lutea were counted according to the sections. Data are reported as means \pm SE. Statistical difference was determined by one-way ANOVA followed by Fisher protected least significant difference (LSD) tests. *Significant difference $(\mathrm{P}<0.05)$ compared with other groups.

\section{RIA for serum estradiol and progesterone}

Sera were collected at the metestrus stage of the estrous cycle to detect concentrations of estradiol and progesterone by RIA. As shown in Figure 6, significant differences were observed in estradiol and progesterone concentrations between the $\mathrm{T} 1$ and Con groups $(\mathrm{P}<0.05)$. The estradiol concentration in $\mathrm{T} 1$ was lower than that in Con, whereas the progesterone level in T1 was higher than that in Con. In addition, the concentrations of estradiol and progesterone in $\mathrm{T} 2$ showed no significant differences compared with either T1 or Con. 


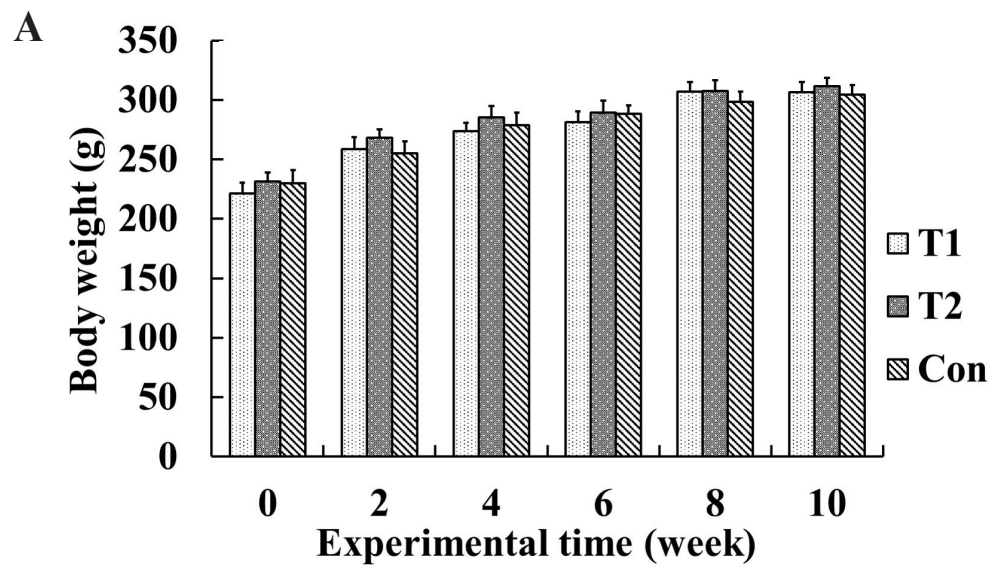

B

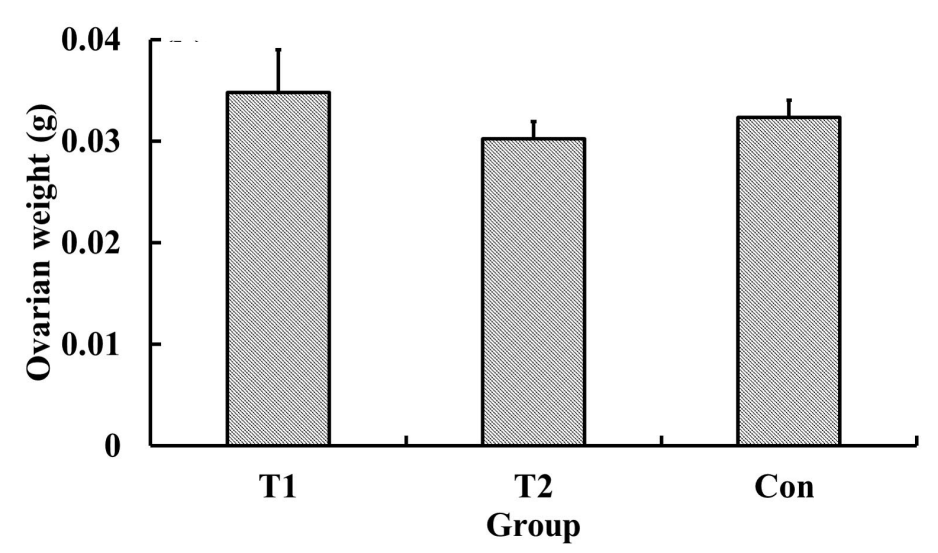

C

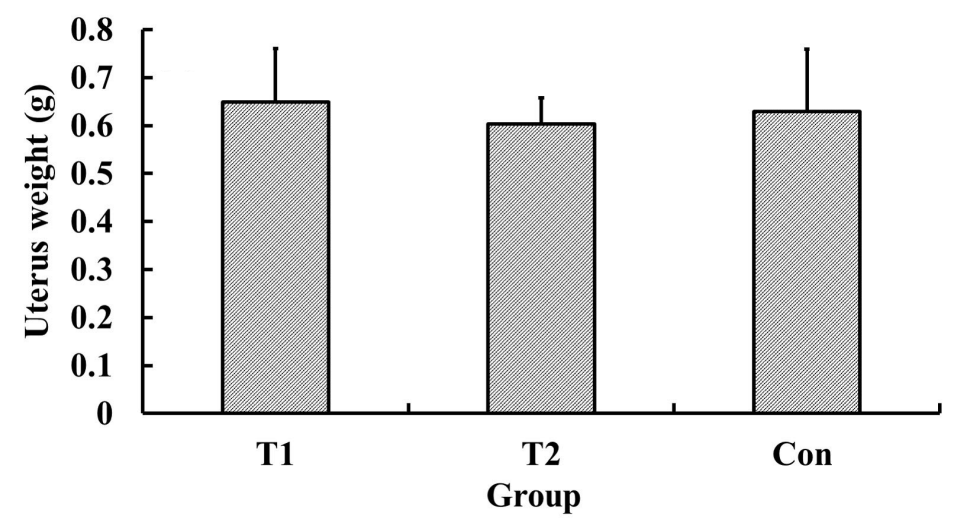

Figure 5. Inhibin DNA vaccine does not affect the weights of body (A), ovary (B) and uterus (C) after immunization. Rats were treated as in Figure 2, and then were sacrificed at metestrus stage after week 10. The body, ovary and uterus were weighted. Data are reported as means \pm SE. Statistical difference was determined by one-way ANOVA followed by Fisher protected least significant difference (LSD) tests. 

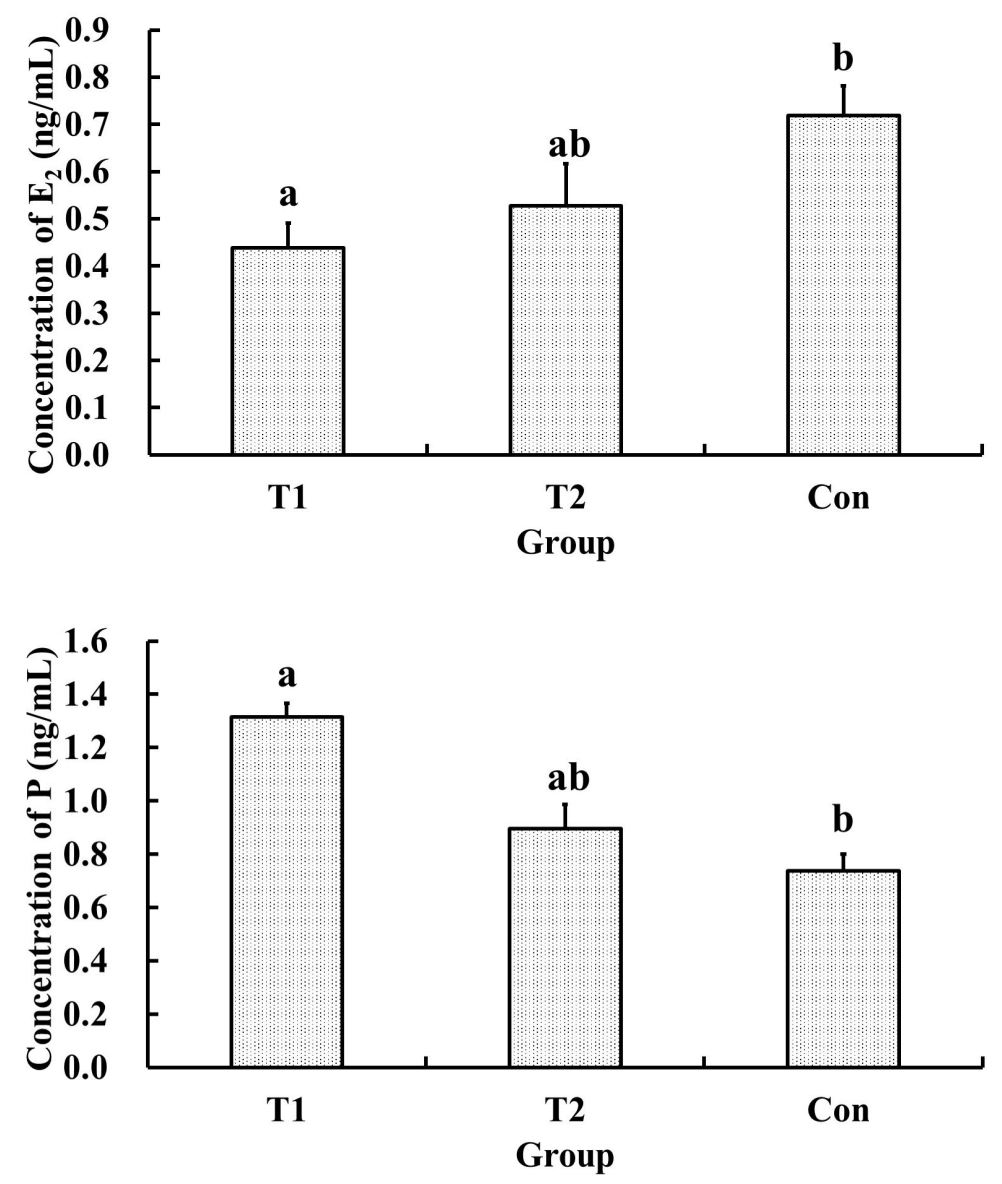

Figure 6. Serum concentrations of estradiol $\left(\mathrm{E}_{2}\right)$ and progesterone $(\mathrm{P})$ after inhibin DNA immunization. Rats were treated as in Figure 2, and then were sacrificed at metestrus stage after week 10. Serum were collected to detect the concentrations of estradiol and progesterone by RIA. Bar with complete different letters denote significant differences $(\mathrm{P}<0.05)$ among groups.

\section{DISCUSSION}

DNA vaccines have been widely used in laboratory animals to elicit comprehensive humoral and cellular immune responses (Tang et al., 1992; Ellis, 2001). However, as they have mainly been applied against various pathogens and tumor antigens (Kutzler and Weiner, 2008), there are only a few reports that have tested their immunity against endogenous antigens of reproduction performance in animals (Han et al., 2008; Wang et al., 2012). As described above, there are some limitations to the recombinant plasmid method, leading to efforts focused on developing novel vaccine vectors such as attenuated Salmonella. In the current study, we used the attenuated bacteria as a vector for the inhibin vaccine. This vaccine was the first used for immunogenicity and safety evaluation in rats. 


\section{Requirements for an inhibin DNA vaccine}

For a vaccine to be successful, it must satisfy several requirements (Donnelly et al., 1997). First, the vaccine should have strong immunogenicity and elicit appropriate immune responses. In addition, immune responses should persist in the absence of repetitive booster immunizations. The vaccine should be sufficiently safe to immunize general individuals. Finally, the vaccine should be adaptable for use against other target pathogens.

In this study, ELISA results showed increased $\mathrm{P} / \mathrm{N}$ values of antibody after primary immunization, suggesting that the vaccine has strong immunogenicity and can elicit humoral immune responses. $\mathrm{P} / \mathrm{N}$ values remained at high levels during the experiment without the third immunization, indicating the immune persistence of the vaccine. For immunization against inhibin, as a reproductive hormone playing key roles in follicular development and the ovulation rate, inhibin antibody production is essential and important; therefore, we examined antibody levels. Bartolomé et al. (2010) used attenuated S. choleraesuis as the bactofection vehicle to deliver the DNA vaccine, leading to the production of specific serum IgG with a persistently high antibody titer. The recombinant vaccine also elicited cell-mediated and mucosal immune responses.

Regarding the biosafety of the vaccine, several concerns have been identified in guidance documents that exist for the clinical use of DNA vaccines (FDA, 2007; WHO, 2007). These concerns relate to genetic, toxicological, and environmental effects.

For genetic effects, the bio-distribution, persistence, and integration into the host genome were considered, which may lead to activation of oncogenes, inactivation of tumor suppressor genes, or to vertical transmission (Schalk et al., 2006). Our previous results showed that most bacteria and plasmids had cleared $8 \mathrm{~h}$ after oral inoculation of inhibin DNA vaccine in mice, although the plasmid may proliferate in different tissues from days 1-4. No plasmid was present on day 14 post-inoculation. In addition, there was no chromosomal integration in the female mouse or her offspring (Zhen YH and Yang LG, unpublished results).

Although attenuated, the vector may retain some residual virulence. Thus, we conducted toxicity and histological studies to examine the potential toxicological effect. The results showed that all rats performed well, and tissue sections showed no pathological changes. Previous studies confirmed that there was no obvious inflammation or side effects after using Salmonella as a DNA vaccine vector (Yang et al., 2005).

As a powerful selection marker, resistance genes to antibiotics in plasmids are discouraged by regulatory authorities (EMA, 2008) because the plasmid may spread resistance genes. This is a possible environmental risk of using a DNA vaccine. In our study, we employed a non-antibiotic-based system (host-vector balanced lethal system), which used an auxotrophicone in the S. choleraesuis C500 strain (with deletion of the asd gene) as the vector that could survive in minimal media only after containing a plasmid encoding asd (pVAXasd). Compared with our previous plasmid, pCIS (Han et al., 2008), this selection system is efficient and can preclude the use of antibiotics (Zhen et al., 2009). In addition, the attenuated bacteria vector can also act as a vaccine for Salmonella, which infects both humans and animals, resulting in enteritis and blood poisoning.

\section{Mechanism of inhibin DNA vaccine}

Several studies have shown that immunization against inhibin increased FSH levels, leading to stimulation of ovarian follicular development and an increased ovulation rate 
(Medan et al., 2003a; Sasaki et al., 2006). Our results showed that the recombinant vaccine increased the amount of corpora lutea in rats, consistent with our previous study that the naked inhibin DNA vaccine can augment the twinning rate in sheep and improve litter size in rats (Han et al., 2008). However, increased ovulation is not always accompanied by an increase in FSH secretion following inhibin immunization (Tannetta et al., 1998; Hennies et al., 2001), indicating a role of inhibin in recruitment of follicles in an auto/paracrine manner. Medan et al. (2003a,b) found that active immunization against inhibin in goats resulted in improved follicular development and ovulation rates, as well as higher pre-ovulatory estradiol and progesterone concentrations in the luteal phase. In our present study, the larger amount of corpora lutea and higher progesterone levels observed at the metestrus stage most likely reflected the increased ovulation rate in immunized rats.

Interestingly, rats with two booster immunizations showed lower $\mathrm{P} / \mathrm{N}$ values than those with only one booster immunization 10 weeks after primary immunization, and the same result was observed for the amount of corpora lutea. These preliminary results suggest that this effect may be related to immunological tolerance. It has been reported that immunological tolerance is an obstacle in the development of oral vaccines (Mowat, 2003). Several factors may favor tolerance, including the nature, concentration, and mode of the antigen presented to the immune system, as well as the age of the host. Ichino et al. (1999) employed a plasmid DNA vaccine encoding the circumsporozoite protein of malaria to immunize newborn rats, inducing tolerance rather than immunity. However, whether this affects the administration through muscular injection requires further research.

\section{CONCLUSIONS}

In the current study, we evaluated the effect of the balanced lethal system for the inhibin vaccine and confirmed its biosafety. The results showed that the vaccine can elicit strong humoral immune responses and enhance ovulation rates, and is biologically safe. In addition, the vaccine can preclude the use of antibiotics and provide protection by the attenuated vector to prevent Salmonella infections in livestock. Most importantly, the attenuated $S$. choleraesuis-mediated inhibin DNA vaccine may be an alternative to naked inhibin plasmids for increasing ovarian follicular development and improving animal fertility.

\section{ACKNOWLEDGMENTS}

We express our gratitude to Dr. Xia Y, The Chinese University of Hong Kong, for reading the original manuscript and offering valuable suggestions. Research supported by the Open-Ended Fund for the Youth of China Agricultural University-Nanjing Agricultural University (\#NC2008005).

\section{REFERENCES}

Avital-Cohen N, Heiblum R, Argov N, Rosenstrauch A, et al. (2012). The effect of active immunization against vasoactive intestinal peptide (VIP) and inhibin on reproductive performance of aging White Leghorn roosters. Poult. Sci. 91: 161-174.

Bartolomé A, Herrero-Gil A, Horcajo P, Orden JA, et al. (2010). Salmonella enterica serovar Choleraesuis derivatives harbouring deletions in rpoS and phoP regulatory genes as vehicles for DNA vaccines. Vet. Microbiol. 141: 81-88. 
de Kretser DM, Meinhardt A, Meehan T, Phillips DJ, et al. (2000). The roles of inhibin and related peptides in gonadal function. Mol. Cell Endocrinol. 161: 43-46.

Donnelly JJ, Ulmer JB and Liu MA (1997). DNA vaccines. Life Sci. 60: 163-172.

Ebel GD, Dupuis AP, Nicholas D, Young D, et al. (2002). Detection by enzyme-linked immunosorbent assay of antibodies to West Nile virus in birds. Emerg. Infect. Dis. 8: 979-982.

Ellis RW (2001). Technologies for the design, discovery, formulation and administration of vaccines. Vaccine 19: 26812687.

EMA (2008). Overview of Comments Received on Guideline on Non-Clinical Studies Required Before First Clinical Use of Gene Therapy Medicinal Products. European Medicines Agency Doc. Ref. EMEA/CHMP/GTWP/65260/2008.

FDA (US Food and Drug Administration) (2007). Guidance for Industry: Considerations for Plasmid DNA Vaccines for Infectious Disease Indications. Freedom of Information Staff, Food and Drug Administration, Rockville.

Galen JE, Wang JY, Chinchilla M, Vindurampulle C, et al. (2010). A new generation of stable, nonantibiotic, low-copynumber plasmids improves immune responses to foreign antigens in Salmonella enterica serovar Typhi live vectors. Infect. Immun. 78: 337-347.

Greenland JR, Geiben R, Ghosh S, Pastor WA, et al. (2007). Plasmid DNA vaccine-elicited cellular immune responses limit in vivo vaccine antigen expression through Fas-mediated apoptosis. J. Immunol. 178: 5652-5658.

Han L, Mao DG, Zhang DK, Liang AX, et al. (2008). Development and evaluation of a novel DNA vaccine expressing inhibin alpha (1-32) fragment for improving the fertility in rats and sheep. Anim. Reprod. Sci. 109: 251-265.

Hennies M, Voglmayr JK, Dietrich E, Stollmann M, et al. (2001). Hormonal response of female goats to active immunization against a recombinant human inhibin alpha-subunit, and establishment of an enzyme-linked immunosorbent assay for caprine follicle-stimulating hormone. Reprod. Domest. Anim. 36: 65-71.

Huang Y, Chen A, Li X, Chen Z, et al. (2008). Enhancement of HIV DNA vaccine immunogenicity by the NKT cell ligand, alpha-galactosylceramide. Vaccine 26: 1807-1816.

Ichino M, Mor G, Conover J, Weiss WR, et al. (1999). Factors associated with the development of neonatal tolerance after the administration of a plasmid DNA vaccine. J. Immunol. 162: 3814-3818.

Kutzler MA and Weiner DB (2008). DNA vaccines: ready for prime time? Nat. Rev. Genet. 9: 776-788.

Kwon YM, Cox MM and Calhoun LN (2007). Salmonella-based vaccines for infectious diseases. Expert. Rev. Vaccines 6: $147-152$.

Li C, Zhu YL, Xue JH, Zhang SL, et al. (2009). Immunization against inhibin enhances both embryo quantity and quality in Holstein heifers after superovulation and insemination with sex-sorted semen. Theriogenology 71: 1011-1017.

Li DR, Qin GS, Wei YM, Lu FH, et al. (2011). Immunisation against inhibin enhances follicular development, oocyte maturation and superovulatory response in water buffaloes. Reprod. Fertil. Dev. 23: 788-797.

Medan MS, Watanabe G, Sasaki K, Nagura Y, et al. (2003a). Effects of passive immunization of goats against inhibin on follicular development, hormone profile and ovulation rate. Reproduction 125: 751-757.

Medan MS, Watanabe G, Sasaki K, Nagura Y, et al. (2003b). Ovarian and hormonal response of female goats to active immunization against inhibin. J. Endocrinol. 177: 287-294.

Melkebeek V, Sonck E, Verdonck F, Goddeeris BM, et al. (2007). Optimized FaeG expression and a thermolabile enterotoxin DNA adjuvant enhance priming of an intestinal immune response by an FaeG DNA vaccine in pigs. Clin. Vaccine Immunol. 14: 28-35.

Morris DG, McDermott MG and Sreenan JM (1991). Effect of immunizing prepuberal lambs of low and high ovulation rate genotypes with inhibin partially purified from bovine follicular fluid. Theriogenology 35: 339-350.

Mowat AM (2003). Anatomical basis of tolerance and immunity to intestinal antigens. Nat. Rev. Immunol. 3: 331-341.

O'Shea T, Bindon BM, Forage RG, Findlay JK, et al. (1993). Active immunization of Merino ewe lambs with recombinant bovine alpha inhibin advances puberty and increases ovulation rate. Reprod. Fertil. Dev. 5: 173-180.

Sasaki K, Medan MS, Watanabe G, Sharawy S, et al. (2006). Immunization of goats against inhibin increased follicular development and ovulation rate. J. Reprod. Dev. 52: 543-550.

Schalk JA, Mooi FR, Berbers GA, van Aerts LA, et al. (2006). Preclinical and clinical safety studies on DNA vaccines. Hum. Vaccin. 2: 45-53.

Sewani-Rusike CR and Dakwa C (2000). Fertility in rats immunized with steroid-free bovine follicular fluid. Onderstepoort. J. Vet. Res. 67: 257-262.

Tang DC, DeVit M and Johnston SA (1992). Genetic immunization is a simple method for eliciting an immune response. Nature 356: 152-154.

Tannetta DS, Feist SA, Bleach EC, Groome NP, et al. (1998). Effects of active immunization of sheep against an amino terminal peptide of the inhibin alpha $\mathrm{C}$ subunit on intrafollicular levels of activin A, inhibin A and follistatin. $J$. Endocrinol. 157: 157-168.

Torres-Escobar A, Juárez-Rodríguez MD, Gunn BM, Branger CG, et al. (2010). Fine-tuning synthesis of Yersinia pestis 
LcrV from runaway-like replication balanced-lethal plasmid in a Salmonella enterica serovar typhimurium vaccine induces protection against a lethal $Y$. pestis challenge in mice. Infect. Immun. 78: 2529-2543.

Wang SL, Han L, Ahmad S, Cao SX, et al. (2012). Effect of a DNA vaccine harboring two copies of inhibin alpha (1-32) fragments on immune response, hormone concentrations and reproductive performance in rats. Theriogenology 78 : 393-401.

Wang XL, El-Gayar M, Knight PG and Holtz W (2009). The long-term effect of active immunization against inhibin in goats. Theriogenology 71: 318-322.

WHO (2007). Guidelines for Assuring the Quality and Nonclinical Safety Evaluation of DNA Vaccines. World Health Organization Technical Report Series No. 941.

Yang XL, Liu WC, Yang WW, Zhong D, et al. (2005). Oral immunization of mice with vaccine of attenuated Salmonella typhimurium expressing Helicobacter pylori urease B subunit. Biomed. Environ. Sci. 18: 411-418.

Yang Y, Zhang Z, Yang J, Chen X, et al. (2010). Oral vaccination with Ts87 DNA vaccine delivered by attenuated Salmonella typhimurium elicits a protective immune response against Trichinella spiralis larval challenge. Vaccine 28: 2735-2742.

Zhen Y, Han L, Liang A, Wang Q, et al. (2009). Study on genetic stability of inhibin recombinant plasmid in the attenuated Salmonella choleraesuis C500 strain. Biotechnol. Bull. 300-304. 